OPEN ACCESS

Edited by:

Deanne Helena Hryciw,

Griffith University, Australia

Reviewed by:

Rebecca Maree Dyson,

University of Otago, New Zealand

Marloes Dekker Nitert,

The University of Queensland,

Australia

*Correspondence:

Maria M. Pineyro

mercepin@gmail.com

orcid.org/0000-0003-2083-7839

Specialty section: This article was submitted to

Obesity,

a section of the journal

Frontiers in Endocrinology

Received: 28 July 2020 Accepted: 09 October 2020 Published: 03 November 2020

Citation:

Pereda J, Bove I and Pineyro MM (2020) Excessive Maternal Weight and

Diabetes Are Risk Factors for

Macrosomia: A Cross-Sectional Study of 42,663 Pregnancies in Uruguay.

Front. Endocrinol. 11:588443.

doi: 10.3389/fendo.2020.588443

\section{Excessive Maternal Weight and Diabetes Are Risk Factors for Macrosomia: A Cross-Sectional Study of 42,663 Pregnancies in Uruguay}

\author{
Jimena Pereda ${ }^{1}$, Isabel Bove ${ }^{2}$ and Maria M. Pineyro ${ }^{1 *}$ \\ 1 Clinica de Endocrinología y Metabolismo, Hospital de Clínicas, Facultad de Medicina, Universidad de la República, \\ Montevideo, Uruguay, ${ }^{2}$ Departamento de Ciencias Cognitivas y de la Salud, Universidad Católica del Uruguay, Montevideo, \\ Uruguay
}

Objective: To evaluate the risk of macrosomia in newborns from women with gestational diabetes, pregestational diabetes, overweight, and obesity in Uruguay in 2012, as well as its association with prolonged pregnancy, maternal age, multiparity, and excessive gestational weight gain (EGWG).

Methods: We performed a cross-sectional study of 42,663 pregnant women. The risk of macrosomia was studied using logistic regression.

Results: Mean maternal age was $26.7 \pm 6.8$ years. Pregestational overweight and obesity was present in $20.9 \%$ and $10.7 \%$ of women, respectively. There were $28.1 \%$ and $19.8 \%$ of women overweight and obese at the end of the pregnancy, respectively. Furthermore, 0.5\% had pregestational diabetes and $8.5 \%$ were multiparous. Twenty two percent developed gestational diabetes and $44.9 \%$ had EGWG. The prevalence of macrosomia was $7.9 \%$, significantly more prevalent in males $(10.0 \%$ vs. $5.5 \%, p<0.005)$. Univariate analysis showed that obesity and overweight pre-pregnancy, obesity and overweight at the end of pregnancy, EGWG, pregestational diabetes, gestational diabetes, multiparity, prolonged pregnancy, and male newborn were strongly associated with macrosomia $(p<0.0001)$. Maternal age $>35$ years did not increase the risk of macrosomia. After multiple logistic regression macrosomia was more likely in pre-gestational obese women (OR 1.24; $\mathrm{Cl}$ 1.07-1.44), overweight women at the end of pregnancy (OR 1.66; Cl 1.46-1.87), obese women at the end of pregnancy (OR 2.21; Cl 1.90-2.58), women with EGWG (OR 1.78; Cl 1.59-1.98), pregestational diabetes (OR 1.75; Cl 1.15-2.69), gestational diabetes (OR 1.39; Cl 1.25-1.53), prolonged pregnancy (OR 2.67; Cl 2.28-3.12), multiparity (OR 1.24; $\mathrm{Cl} 1.04-1.48$ ), and male newborn (OR 1.89; $\mathrm{Cl} 1.72-2.08$ ).

Conclusion: Maternal overweight, obesity, EGWG, and gestational diabetes are prevalent in Uruguay, increasing the risk of macrosomia. Efforts to implement strategies 


\section{to decrease the prevalence of overweight and obesity among women of reproductive age} are essential to improve maternal and neonatal outcomes.

Keywords: overweight, obesity, pregnancy, gestational diabetes, pregestational diabetes, macrosomia

\section{INTRODUCTION}

Fetal macrosomia is defined as neonate birthweight $\geq 4,000 \mathrm{~g}$ and large for gestational age as birthweight above the $90^{\text {th }}$ centile. Worldwide prevalence of fetal macrosomia is approximately $9 \%$, with broad variations between countries (1). In Uruguay it is reported in $6 \%$ to $11.1 \%$ of newborns $(2,3)$.

Macrosomia is associated with maternal and fetal complications such as preterm birth, postpartum hemorrhage, maternal birth canal trauma, a higher risk of cesarean delivery, shoulder dystocia, fetal asphyxia, and neonatal hypoglycemia (4-6). In addition, it increases the risk of developing obesity, insulin resistance, metabolic syndrome, and cancer later in life (7-9).

Maternal overweight, excessive gestational weight gain and gestational diabetes are known risk factors for macrosomia. The prevalence of obesity and gestational diabetes is increasing worldwide. In the United States between $18.5 \%$ and $38.3 \%$ of women are obese at conception or delivery $(10,11)$.

In Uruguay, a survey of 900 randomly selected adults reported $53 \%$ of women with body mass index (BMI) $\geq 25 \mathrm{~kg} /$ $\mathrm{m}^{2}$. Fourteen percent of women between 18 and 35 years were overweight, and $8 \%$ obese. Moreover, 33\% of women between 36 and 45 years were overweight and $22 \%$ obese (12).

Diabetes affects $6 \%-9 \%$ of pregnancies, the majority (99\%) having gestational diabetes $(13,14)$. Moreover, with the new diagnostic criteria for diabetes in pregnancy adopted by the International Association of Diabetes and Pregnancy Study Groups (IADPSG), World Health Organization (WHO), and American Diabetes Association (ADA) the prevalence of hyperglycemia in pregnancy has increased to an estimated of $17 \%$ (15). This new diagnostic criteria was based on The Study of Hyperglycemia and Adverse Pregnancy Outcomes (HAPO) which demonstrated a linear continuous correlation between levels of maternal blood glucose and adverse perinatal outcomes (16).

Maternal overweight and obesity regularly coexist with gestational diabetes. Obesity and gestational diabetes are recognized risk factors for adverse pregnancy outcomes such as preterm delivery, hypertension, primary cesarean delivery, and large for gestational age fetuses and macrosomia $(17,18)$.

Infants of women with obesity or gestational diabetes are at an increased risk of becoming overweight or obese at a young age and are more likely to develop type 2 diabetes, metabolic syndrome and cancer later in life $(19,20)$. In a cohort of 23832 Uruguayan women who delivered babies from 2010 to 2012 there were $23.6 \%$ and $9.4 \%$ women overweight and obese prepregnancy, respectively. In addition, high pre-gestational BMI and EGWG were significantly associated with macrosomia in this cohort.

The aim of this study was to evaluate the risk of macrosomia in newborns from women with gestational diabetes (GD) and overweight/obesity in Uruguay in 2012, as well as it association with prolonged pregnancy, maternal age and multiparity. In addition, we evaluated prevalence and risk of macrosomia in newborns from mothers with pregestational diabetes (PGD) and from those with EGWG.

\section{MATERIALS AND METHODS}

We performed an observational and cross-sectional study of 42, 663 pregnant women and their newborns in Uruguay in 2012. There where 45,790 SIP valid forms form pregnant women, with 3157 (6.9\%) cases meeting exclusion criteria. The data was collected from the Perinatal Information System (SIP) records, which are managed by the Latin American Center for Perinatology, Women and Reproductive Health (CLAP), a unit from the WHO. The SIP was established in 2000 and its use became mandatory in 2009. A structured form, which includes exhaustive data of the pregnancy and delivery as well as perinatal health of the newborn, is completed by the gynecologist during pregnancy and by the delivery hospital. Data form the SIP of all maternity hospitals of the country was analyzed.

Exclusion criteria included abortion, stillbirth, multiple pregnancy, gestation less than 22 weeks, and extreme values in maternal weight (pre-pregnancy weight or at end of gestation less than $35 \mathrm{~kg}$ or more than $200 \mathrm{~kg}$ or BMI less than $14 \mathrm{~kg} / \mathrm{m}^{2}$ or more than $60 \mathrm{~kg} / \mathrm{m}^{2}$ ). In addition, extreme values in neonatal birth weight where excluded (less than 600 gr or more than $6.500 \mathrm{~g}$ ), as well as those records without data birth weight.

Pre-pregnancy BMI $(\mathrm{kg} / \mathrm{m} 2)$ was defined as follows: $<18.5=$ underweight; $18.5-24.9$ = normal weight; $25-29.9$ = overweight; 30 or higher $=$ obesity.

Gestational weight gain was calculated as the difference between weight at delivery and pre-pregnancy self-reported weight. Excessive gestational weight gain was considered when it exceeded the total weight gain recommendations from the Institute of Medicine (IOM). Gestational weight gain according to the IOM consists of: 1) underweight: $12.5-18.0 \mathrm{~kg}$; 2) normal weight: $11.5-16.0 \mathrm{~kg}$; 3) overweight: $7.0-11.5 \mathrm{~kg}$; and 4) obese: $5.0-9.0 \mathrm{~kg}$. Body mass index at the end of gestation was calculated with last recorded pregnancy weight available in the last follow up, defined as the prenatal visit within 2 weeks of delivery. Categories of nutritional status where defined relying on a modified chart by Atalah et al. based on longitudinal studies in Chile and adopted by Latin American countries (21). Categories based on BMI at the end of pregnancy consists of: 1) normal weight: $25.00-29.00 ; 2$ ) overweight: $29.10-33.10$; and 3 ) obese: $>33.10$.

Diabetes was categorized as gestational diabetes according to IADPSG criteria of fasting glucose $\geq 92 \mathrm{mg} / \mathrm{dl}$, as information on 
2-h glucose after an oral glucose tolerance test (OGTT) is not available in the SIP records. Fasting glucose levels are recorded before 20 weeks and after 20 weeks of gestation in the SIP form. Older maternal age was defined as women aged 35 years or older. Multiparity was considered when women had three or more live births. Prolonged pregnancy was defined as the one that persisted beyond 41 weeks of gestation. Macrosomia was defined as birth weight equal or above 4000 grams.

The association of qualitative variables was performed by Pearson's Chi-square test and the risk of macrosomia was studied using a model of binary logistic regression, expressed as odds ratios (OR) with $95 \%$ confidence intervals (95\% CI). The tests were considered statistically significant at an alpha level $(\alpha)$ of $0,05(p<0,05)$. Multiple regression analysis was done to estimate the relative contribution of independent variables found to be significant in univariate analysis (overweight and obesity pre-pregnancy and at the end pregnancy, EGWG, pregestational and gestational diabetes, multiparity, prolonged pregnancy, and male newborn) to macrosomia (adjusted ORs). We examined potential collinearity using variance inflation factors (VIF) and tolerance test (TT). Results indicated very low levels of multicollinearity with a maximum VIF at $<2.2$ and $\mathrm{TT}>0.2$, expect for normal weight at the end of pregnancy so it was excluded from multiple regression analysis (it provided redundant information). In addition, we performed forward and backward stepwise regression, with the variables without a statistical relationship progressively eliminated. Both forward and backward selections yield the same results.

Statistical analysis was performed with SPSS version 17.0. The de-identified SIP data was provided by the Uruguayan Ministry of Public Health; its analysis was not subject to human subjects review.

\section{RESULTS}

We evaluated 42,663 singleton deliveries in 2012 in Uruguay. Mean maternal age was $26.7 \pm 6.8$ years. Population demographics are shown in Table 1.

Pre-gestational overweight and obesity was recorded in $20.9 \%$ and $10.7 \%$ of women, respectively. There were $28.1 \%$ and $19.8 \%$ of women overweight and obese at the end of the pregnancy, respectively. Twenty-three percent of women $(n=5219)$ with normal weight at the beginning of the pregnancy were overweight at the end it, as well as $34.4 \%(n=2638)$ of those overweight pre-pregnancy ended up being obese over the course of it. Excessive gestational weight gain was more prevalent in women being overweight or obese before pregnancy (Table 2).

Furthermore, $0.5 \%$ had PGD, 22\% developed GD, and almost half had EGWG. Gestational diabetes was present in one third of women with obesity before pregnancy, and in $18 \%$ of those without it.

The prevalence of macrosomia was $7.9 \%$, significantly more prevalent in males $(10.0 \%$ vs. $5.5 \%, \mathrm{p}<0.005)$. Macrosomia was more prevalent in obese women at the end of pregnancy (Figure 1).
TABLE 1 | Population demographics.

\begin{tabular}{lc}
\hline Variable & Total $(\mathbf{n}=\mathbf{4 2 , 6 6 3 )}$ \\
\hline Age (y) & $26.7 \pm 6.8$ \\
Age $>35(\mathrm{y})$ & $4629(10.9)$ \\
BMl pre-pregnancy & $24.0 \pm 4.8$ \\
BMl at end of pregnancy & $29.1 \pm 4.9$ \\
Weight gain (kg) & $14.3 \pm 6.9$ \\
Prolonged pregnancy & $2086(4.9)$ \\
Multiparous & $3634(8.5)$ \\
Diabetes (DM) & \\
$\quad$ Pre-gestational & $304(0.7)$ \\
Gestational & $9252(22)$ \\
Pre-pregnancy weight & \\
Overweight & $7667(20.9)$ \\
Obese & $3965(10.7)$ \\
Weight at end of pregnancy & \\
Overweight & $9860(28.1)$ \\
Obese & $6951(19.8)$ \\
Excessive gestational weight gain & $11422(44.9)$ \\
Gestational age (weeks) & $38.5 \pm 1.9$ \\
Male newborn & $21802(51.2)$ \\
\hline
\end{tabular}

Data are $n(\%)$, mean $\pm S D$.

TABLE 2 | Population demographics according to pre-pregnancy weight.

\begin{tabular}{lccc}
\hline Variable & $\begin{array}{c}\text { Normal weight } \\
\text { (n = 22588) }\end{array}$ & $\begin{array}{c}\text { Over weight } \\
(\mathbf{n}=\mathbf{7 6 6 7 )}\end{array}$ & $\begin{array}{c}\text { Obese } \\
\text { (n = 3965) }\end{array}$ \\
\hline Age (years) & $26.4 \pm 6.7$ & $27.9 \pm 6.6$ & $28.8 \pm 6.4$ \\
& $(12-48)$ & $(12-50)$ & $(14-48)$ \\
BMl & $21.8 \pm 1.7$ & $27.1 \pm 1.4$ & $34.3 \pm 4.3$ \\
Excessive & $5937(26.3)$ & $3339(44.3)$ & $1560(39.3)$ \\
gestational weight & & & \\
gain & & & $38.4 \pm 2.0$ \\
Gestational age of & $38.5 \pm 1.8$ & $38.6 \pm 1.8$ & $(23-42)$ \\
newborn (weeks) & $(23-42)$ & $(22-42)$ & $3404.0 \pm 628.6$ \\
Birth weight (grams) & $3259.8 \pm 538.9$ & $3361.2 \pm 565.5$ & $(700-5970)$ \\
Birth weight (grams) & $(670-5290)$ & $(675-6000)$ & \\
percentiles & & & 3450 \\
$\quad$ P50 & 3290 & 3400 & 3795 \\
P75 & 3600 & 3710 & 4125 \\
P90 & 3880 & 4010 & $593(15.0)$ \\
Macrosomia & $1458(6.5)$ & $788(10.3)$ & $2048(51.7)$ \\
Male newborn & $11513(51.0)$ & $3923(51.2)$ & \\
\hline
\end{tabular}

Data are $n(\%)$, mean $\pm S D$ (range).

Table 3 shows frequency of macrosomia related to clinical factors. Univariate analysis showed that obesity and overweight pre-pregnancy, obesity, and overweight at the end of pregnancy, EGWG, PGD, GD, multiparity, prolonged pregnancy, and male newborn were strongly associated with macrosomia $(\mathrm{p}<0.0001)$. Maternal age $>35$ years did not increase the risk of macrosomia (Table 3).

A multiple logistic regression was performed to evaluate the independent association between the exposure variables and macrosomia (Table 4). The logistic regression model was statistically significant, $x^{2}(9)=1021,404, p<0001$.

Women classified as obese pre-pregnancy (14.9\% vs. $6.1 \%$; OR 1.24 CI 1.07-1.45), overweight at the end of pregnancy $(9.6 \%$ vs. $4.4 \%$, OR 1.66; CI 1.46-1.87), and obese at the end of pregnancy ( $15 \%$ vs. $4.4 \%$, OR 2.21 ; CI $1.90-2.58)$ were at 


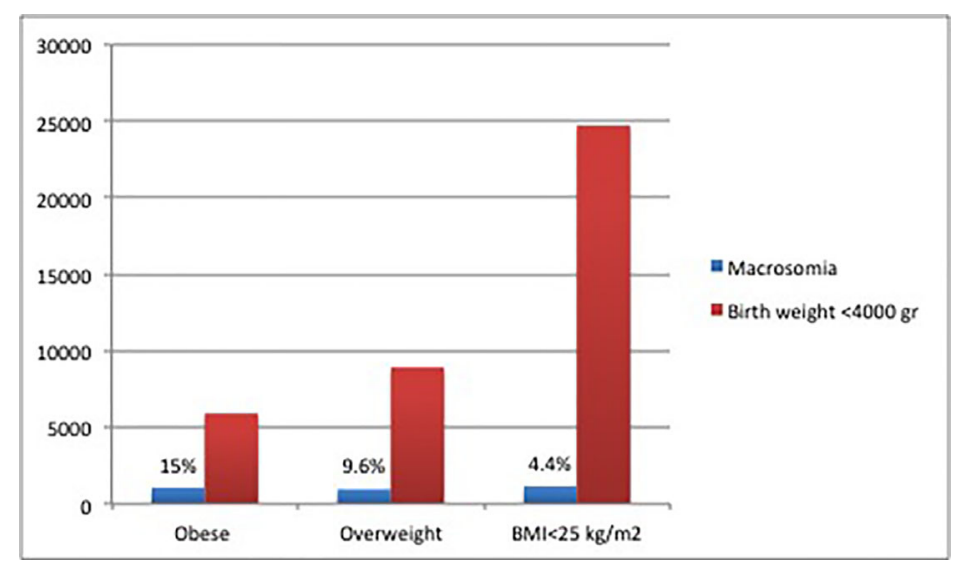

FIGURE 1 | Prevalence of macrosomia related to birth weight at the end of pregnancy.

TABLE 3 | Incidence of primary outcome according to clinical factors.

\begin{tabular}{|c|c|c|c|c|c|c|c|}
\hline \multirow[t]{2}{*}{ Variable } & \multirow{2}{*}{$\begin{array}{c}\text { Total N } \\
\mathbf{N}\end{array}$} & \multicolumn{2}{|c|}{ No macrosomia } & \multicolumn{2}{|c|}{ Macrosomia N\% } & \multirow{2}{*}{$\begin{array}{c}\text { Crude } \\
\text { OR }(95 \% \text { Cl) }\end{array}$} & \multirow[t]{2}{*}{$\mathbf{p}$} \\
\hline & & $\mathbf{N}$ & $\%$ & $\mathbf{N}$ & $\%$ & & \\
\hline Age $>35$ years & 4629 & 4237 & 91.5 & 392 & 8.5 & $1.09(0.98-1.22)$ & 0.124 \\
\hline Obese pre-pregnancy & 3965 & 3374 & 85.1 & 591 & 14.9 & $2.27(2.06-2.50$ & $<.0001$ \\
\hline Overweight pre-pregnancy & 7667 & 6852 & 89.4 & 815 & 10.6 & 1.51(1.39-1.64) & $<.0001$ \\
\hline Obesity at end of pregnancy & 6951 & 5902 & 84.9 & 1049 & 15.1 & $2.68(2.47-2.90)$ & $<.0001$ \\
\hline Overweight at end of pregnancy & 9860 & 8918 & 90.4 & 942 & 9.6 & $1.33(1.22-1.44)$ & $<.0001$ \\
\hline Normal weight at end of pregnancy & 18268 & 17458 & 95.6 & 810 & 4.4 & $0.35(0.32-0.38)$ & $<.0001$ \\
\hline Excessive gestational weight gain & 11422 & 9937 & 87.0 & 1485 & 13.0 & 2.53(2.32-2.77) & $<.0001$ \\
\hline Pregestational diabetes & 304 & 260 & 85.5 & 44 & 14.5 & $2.01(1.46-2.77)$ & $<.0001$ \\
\hline Gestational diabetes & 9252 & 8235 & 89.0 & 1017 & 11.0 & $1.60(1.48-1.73)$ & $<.0001$ \\
\hline Multiparity & 3634 & 3272 & 90.0 & 362 & 10.0 & 1.33(1.18-1.49) & $<.0001$ \\
\hline Prolonged pregnancy & 2086 & 1678 & 80.4 & 408 & 19.6 & $3.09(2.75-3.46)$ & $<.0001$ \\
\hline Male newborn & 21802 & 19628 & 90.0 & 2174 & 10.0 & $1.83(1.70-1.97)$ & $<.0001$ \\
\hline
\end{tabular}

TABLE 4 | Multiple logistic regression analysis: macrosomia and significant confounding variables.

\begin{tabular}{|c|c|c|c|c|}
\hline Variable & $\begin{array}{c}\text { Frequency of } \\
\text { Macrosomia } \\
\text { (\%) }\end{array}$ & Wald & aOR (95\% Cl) & P value \\
\hline $\begin{array}{l}\text { Obese pre- } \\
\text { pregnancy }\end{array}$ & 14.9 & 7.715 & $1.24(1.07-1.44)$ & 0.005 \\
\hline $\begin{array}{l}\text { Obesity at end } \\
\text { of pregnancy }\end{array}$ & 15.0 & 102.068 & $2.21(1.90-2.58)$ & $<0.0001$ \\
\hline $\begin{array}{l}\text { Overweight at } \\
\text { end of } \\
\text { pregnancy }\end{array}$ & 9.6 & 64.688 & $1.66(1.46-1.87)$ & $<0.0001$ \\
\hline $\begin{array}{l}\text { Excessive } \\
\text { gestational } \\
\text { weight gain }\end{array}$ & 13.0 & 102.551 & $1.78(1.59-1.98)$ & $<0.0001$ \\
\hline $\begin{array}{l}\text { Pre-gestational } \\
\text { diabetes }\end{array}$ & 14.5 & 6.662 & 1.75 (1.15-2.69) & 0.010 \\
\hline $\begin{array}{l}\text { Gestational } \\
\text { diabetes }\end{array}$ & 11.0 & 39.190 & 1.39 (1.25-1.53) & $<0.0001$ \\
\hline Multiparity & 10.0 & 5.623 & $1.24(1.04-1.48)$ & 0.018 \\
\hline $\begin{array}{l}\text { Prolonged } \\
\text { pregnancy }\end{array}$ & 19.6 & 151.575 & $2.67(2.28-3.12)$ & $<0.0001$ \\
\hline Male newborn & 10.0 & 175.021 & 1.89 (1.72-2.08) & $<0.0001$ \\
\hline
\end{tabular}

aOR, adjusted OR; Adjusted for overweight and obesity pre-pregnancy and at the end pregnancy, EGWG, pre-gestational and gestational diabetes, multiparity, prolonged pregnancy, and male newborn. increased risk for macrosomia. Obesity was an important independent predictor of macrosomia (OR 1.24), even higher if the women were obese at the end of pregnancy (OR 2.2) compared to women without obesity. Maternal overweight before pregnancy was not significantly associated with macrosomia, once adjusted for the other risks factors (OR 0.97; CI 0.85-1.11).

Macrosomia in newborns from mothers with EGWG was $13 \%$, compared with $5.6 \%$ in those with normal weight gain. The odds of developing macrosomia among women with EGWG was 1.78 (CI 1.59-1.98).

Removing overweight at the end of pregnancy from the model decreased the prediction for obesity at the end of pregnancy (OR from 2.21 to 1.57) but increased the odds of macrosomia for women with excessive gestational weight gain (form 1.78 to 2.12 ).

Removing obesity at the end of pregnancy from the model decreased the prediction for overweight at the end of pregnancy (OR from 1.66 to 1.19) but increased the odds of macrosomia for women with obesity pre-pregnancy (OR from 1.24 to 1.95 ) and excessive gestational weight gain (form 1.17 to 2.31 ).

Macrosomia was present in $14.5 \%, 11 \%$, and $7 \%$ of newborns from mothers diagnosed with PGD, GD, and normal glucose 
status, respectively. Diabetes was an independent predictor of macrosomia, with a 1.7-fold increased risk of macrosomia among women with PGD, and of 1.4-fold in women with GD.

Other risk factors for macrosomina included women with prolonged pregnancy (OR 2.67; CI 2.28-3.12) and multiparity (OR 1.24; CI 1.04-1.48). Compared with gestational age less than 39 weeks there was a 2.7 -fold increase in macrosomia when gestation was beyond 41 weeks.

\section{DISCUSSION}

In this large Uruguayan cohort of pregnant women obesity, excessive gestational weight gain and diabetes increased the risk of macrosomia in the newborn. Moreover, this risk was significantly increased in overweight women at the end of pregnancy. These variables were independent predictors of macrosomia when adjusted for known risk factors. In this study, one third of women had BMI $\geq 25 \mathrm{~kg} / \mathrm{m}^{2}$ before pregnancy. In addition, almost half were overweight or obese at the end of it.

Overweigh and obesity pre-pregnancy was frequent in our cohort similar to that reported in other studies in Uruguay (12). For example, in a national survey of risk factors for noncommunicable diseases performed in 2013, 27.1\% of women between 15 and 24 years were overweight and $12.0 \%$ obese. In addition, $32.7 \%$ women between 25 and 64 years were overweight and $29.2 \%$ obese (22).

Several studies have reported maternal obesity as an independent risk factor for newborn macrosomia (17, 23-25). Pre-gestational BMI is a documented factor that affects fetal growth (26-28). In our study obese women before pregnancy were more likely to deliver marcrosomic offspring. Koyanagi et al. in a survey in 23 developing countries in Africa, Asia, and Latin America reported that BMI significantly increased the risk of macrosomia (29).

Maternal pre-pregnancy obesity may contribute to macrosomia due to increased insulin resistance, which leads to enhanced hepatic glucose production and cause high fetal glucose and insulin concentrations (30). Fleten et al. found a direct association between pre-pregnancy BMI and birthweight in 43,705 Norwegian women, with a 20.3-g increase birthweight for a oneunit increase of BMI (31). In addition, a systematic review and meta-analysis of 31 studies with 1,443,499 women showed that maternal obesity is associated with fetal overgrowth with an increased odds of $117 \%$ for delivering a newborn with a birthweight $\geq 4000 \mathrm{~g}$ (32). In addition, in a cohort of 51,420 Uruguayan women that delivered between 2010-2012 those who where overweight or obese at the beginning and at the end of pregnancy gave birth to significantly more newborns that weighted $>4250 \mathrm{~g}$ (33). However, few studies come from countries in South America (28, 29, 32, 34-37).

In some studies overweight women before pregnancy did not have this increased risk after adjusting for gestational weight gain $(27,38)$. In our study overweight women did not have an increased risk of macrosomia after adjusting for obesity at the end of pregnancy and excessive gestational weight gain. Excessive gestational weight gain is a well-recognized risk factor of macrosomia, independent of pre-pregnancy BMI (27, 39). Although overweight and obese women have the greatest prevalence of EGWG, also those with normal BMI have excess morbidity when gestational weight gain is excessive. Swank et al. reported that excessive BMI changes increased the risk of macrosomia with normal weight women having the greatest odds for macrosomia (aOR 3.85) (40). In addition, in a cohort of 23,832 Uruguayan women those with the highest changes in pregnancy weight had the greatest risk for macrosomia (3).

In our study EGWG increased 1.77 times the risk of macrosomia. However, we did not analyzed risk of macrosomia in women with EGWG according to pre-pregnancy BMI. Moreover, EGWG may have longer-term consequences in offspring. It has been associated with greater offspring BMI and higher systolic blood pressure in early adulthood as well as obesity in the first decade of life $(41,42)$. Hillier et al. found that the attributable risk for childhood obesity was $16.4 \%$ for excessive gestational weight gain (41). In addition, Sridhar el al. reported that excessive gestational weight gain was associated with $46 \%$ increase in odds of having overweight/obesity at 2-5 years, independent of gestational diabetes (43). In our cohort almost half women had EGWG. In an analysis of gestational weight gain of $30 \%$ of births in the United States from 2010-2011, the found that $47.2 \%$ had EGWG (44). Equally important, obese and overweight women had the uppermost excessive gestational weight gain.

Prevalence of gestational diabetes in this cohort was $22 \%$, higher than the estimated $17 \%$ with new diagnostic IADPSG criteria adopted in 2010. Moreover, we want to highlight that this prevalence is underestimated, as data on 2-h glucose post OGTT is not available in the SIP records. A review of the global prevalence of GD between 2005 and 2015 revealed the highest prevalence in the Middle East and North Africa with a median estimate of $12.9 \%$, followed by Southeast Asia (11.7\%), Western Pacific (11.7\%), South and Central America (11.2\%), Africa (8.9\%), and North America and Caribbean (7\%). Europe had the lowermost prevalence with a median of 5.8\% (45). An update of the latter review including studies from 2015 to 2018 showed a median prevalence of $15.2 \%$ in Middle East and North Africa, $15.0 \%$ in Southeast Asia, $10.3 \%$ in Western Pacific, $11.2 \%$ in South and Central America, 7.0\% in North America and the Caribbean, and $6.1 \%$ in Europe (46). However, these estimates comparing different countries between 2005 and 2018 used varied screening and diagnostic values, as IADPSG criteria was proposed in 2010 and adopted by the WHO in 2013 and it is not universally accepted. The only reported prevalence in Uruguay is from a survey of 47 countries to assess its frequency globally published in 2012, which reported a $4.2 \%$ of GD (47). To our knowledge, no other data on prevalence of GD in Uruguay has been published.

Prevalence of GD has been reported to be increasing over time in different countries, probable due to increase in obesity and maternal age $(48,49)$. Obesity prevalence is increasing in Uruguay reflecting a growing trends worldwide $(22,50,51)$. 
Prevalence of gestational diabetes varies by pre-pregnancy BMI, ranging from 3.6\% among normal weight women (BMI 18.5-24.9) to $8.8 \%$ for class I and $13.9 \%$ for class III obesity (52). In our cohort almost $1 / 3$ of patients had BMI $\geq 25 \mathrm{~kg} / \mathrm{m} 2$ before pregnancy, and almost half where overweight or obese at the end of it.

Furthermore, using lower fasting glucose level thresholds supported by IADSPS identifies 6 to 11 -fold more women with GD as compared to previous diagnostic criteria (53). Prevalence of PGD was similar to that reported in the literature (49). In Uruguay, in women between 15-24 and 25-64 years, diabetes has been reported in $0.4 \%$ and $7.8 \%$ of them, respectively (22). In addition, in a review of 74,420 people seeking the health card of the department of Preventive Medicine in Uruguay diabetes was reported in $1.5 \%$ of women between 15 and 19 years, as well as in $0.9 \%$ and $2.3 \%$ of those between $20-29$ and $30-39$ years of age, respectively (54).

As reported in other studies, PGD and GD where associated with higher prevalence and increased risk of macrosomia. Gestational diabetes has been reported to be an independent risk factor for macrosomia in a meta-analysis (55). As in our study, pregestational diabetes carried higher risk of macrosomia compared to gestational diabetes, as fasting plasma glucose is elevated from early to late pregnancy (56). Maternal hyperglycemia leads to fetal hyperglycemia and pancreatic beta cell hyperplasia and hyperinsulinism, with excess accumulation of fat and accelerated fetal growth (57). In the HAPO study there was an association between increasing maternal glucose with excessive neonatal adiposity (58).

Obesity is a well-recognized risk factor for PGD and GD. Diabetes as well as increased maternal BMI are recognized risk factors for macrosomia, as well as for overweight/obesity at a young age and type 2 diabetes in the offspring $(41,59)$. This may be a vicious cycle as these obese offspring may propagate an abnormal metabolic environment in utero during gestation $(60,61)$. Hillier et al. suggested that an overfed state created by excess glucose or overall calories may imprint the child for an overfed metabolism (41). A developmental programming may affect subsequent generations with a generational transfer of obesity, still in the lack of constant environmental stressors (62). Therefore, it may perpetuate a cycle of metabolic disorders and obesity.

On the contrary, women with GD that reduce their intake or have placental dysfunction due to hyperglycemia can have the opposite effect with gestational undernutrition and future metabolic and cardiovascular programming in postnatal and adult life. This adverse development in utero revealed by low birth weight has been associated with greater risk of cardiovascular disease, lung disease, and polycystic ovary syndrome. In addition, timing of this undernutrition may program susceptibility to disease in different ways. When nutrient restriction occurs in early gestation, it has been associated with adult hypertension, but if ensues during late gestation, it has been related to impaired glucose tolerance, type 2 diabetes, and visceral adiposity $(63,64)$.

Lifestyle interventions directed towards healthy eating and physical activity can have enormous impact on maternal health as well as reduce childhood obesity. Reducing the prevalence of overweight and obesity amid women of reproductive age could reduce macrosomia and gestational diabetes. Preconception care guidelines recommend screening women with annual BMI and counseling and referral accordingly (65). Interventions to prevent excess gestational weight gain during pregnancy may be more feasible as women are more motivated to improve their health behavior (66). However, research about the interventions to improve gestational weight gain has not shown a significant change in perinatal outcomes such as macrosomia $(67,68)$. More research is needed to clarify this point and to evaluate these interventions in the long-term in mothers and offspring.

In addition, treatment of gestational diabetes with diet or insulin was associated with lower risk of macrosomia in a metaanalysis of four randomized controlled trials from developed countries (69). Likewise, glycemic control during pregnancy in pregestational diabetes reduces the risk of macrosomia (70).

Additional recognized risk factors for macrosomia include prolonged pregnancy, multiparity, and male newborn. It has been reported that prolonged pregnancy beyond the expected delivery day is a risk factor for macrosomia, as fetuses gain approximately 150-200 g weekly near term (29, 71, 72). Advanced gestational age ends in a greater birth weight, with macrosomia accounting for $3 \%-10 \%$ of post-term deliveries (73).

Multiparity has been associated with macrosomia maybe due to the fact that birth weight increases with parity, with rates of macrosomia 2-3 times higher than women without this risk factor. There is evidence that with every newborn the weight increase 100 to $150 \mathrm{~g}(29,74)$. Male gender has been associated with increased odds of macrosomia, as male newborns weight more than females at any gestational age (75).

The increased risk of fetal macrosomia and maternal ages is well established (76), related to metabolic changes associated to age (77). We did not find an association between older maternal age and macrosomia. However, we did not consider gestational age at delivery as older maternal women may have delivered at an earlier gestation age decreasing the probability of attaining a $>4 \mathrm{~kg}$ neonate (77).

There are some limitations in our study. First, in the SIP records the information about the 2 -h glucose after an oral glucose tolerance test (OGTT) is not available. Using only fasting blood glucose as diagnostic criteria will miss approximately 5\%-15\% patients with GDM (78). This would lead to an underestimation of the prevalence of GD as well as it effect on the risk of macrosomia. Second, there was no data on glucose control or use of insulin on patients with diabetes, which could affect gestational weight gain. In addition, it may influence macrosomia as appropriate management of GD with nutritional therapy and insulin if not well controlled with diet alone has been reported to reduce its rates (79). Third, pre-pregnancy weight was self-reported, which may have errors in BMI and gestational weight gain. However, self-reported pre-pregnancy weight has been shown to highly correlate with measured weight with average error being small (80). However, women with higher BMI and minority groups are more likely to misreport weight, with obese women being more likely to underestimate their weight. Fourth, no information on physical activity or diet is available in the SIP 
form, which may impact gestational weight gain. Finally, sociodemographic data included in the SIP form (ethnic group, education level and marital status) were not recorded in the majority of cases, so these could not be included in the analysis. As few studies come from Latin America, with reported differences in population characteristic from the other regions where most of the findings in this issue have been published, this information could have been helpful to assess these differences.

We believe this study contributes to the field as few studies about excessive maternal weight before or during pregnancy and risk of macrosomia are coming from South America. Most studies come form Western Europe and North America, with differences in population socioeconomics, ethnics, and educational status, making the results of this study of great relevance. This research highlights the importance of weight management amid women of reproductive age in this region. In addition, there are scant data about diabetes during pregnancy in Latin America, with this study contributing in showing a high occurrence of gestational diabetes as well as its role as a risk factor for macrosomia.

\section{CONCLUSION}

Maternal overweight, obesity, EGWG, and GD are prevalent in Uruguay, increasing the risk macrosomia. Overweight/obesity are recognized risk factors of various other complications such as PGD, GD, and long-term health consequences on offspring health and wellbeing. We believe that efforts to implement strategies to decrease the prevalence of obesity and overweight among women of reproductive age are essential to improve maternal and neonatal outcomes.

\section{REFERENCES}

1. Chauhan SP, Grobman WA, Gherman RA, Chauhan VB, Chang G, Magann $\mathrm{EF}$, et al. Suspicion and treatment of the macrosomic fetus: a review. Am J Obstet Gynecol (2005) 193:332-46. doi: 10.1016/j.ajog.2004.12.020

2. BoveI MI, Cerruti F. Encuesta de lactancia, estado nutricional y alimentación complementaria en niñas y niños menores de 24 meses atendidos por servicios públicos y mutuales de Montevideo y el interior del país. Ministerio de Desarrollo Social: Ministerio de Salud Pública, Ministerio de Desarrollo Social, Red Uruguaya de Apoyo a la Nutrición y Desarrollo Infantil (2007). Retrieved from Ministerio de Desarrollo Social: http://www.bibliotecaunicef. uy/doc_num.php?explnum_id=88.

3. Bove Isabel MSF, Klaps L, Domínguez de Landa A. Asociaciones entre el crecimiento prenatal y la antropometría materna en el Uruguay. Nutricion Hospitalaria (2014) 30:643-9. doi: 10.3305/nh.2014.30.3.7648

4. Das S, Irigoyen M, Patterson MB, Salvador A, Schutzman DL. Neonatal outcomes of macrosomic births in diabetic and non-diabetic women. Arch Dis Child Fetal Neonatal Ed (2009) 94:F419-422. doi: 10.1136/adc.2008.156026

5. Siggelkow W, Boehm D, Skala C, Grosslercher M, Schmidt M, Koelbl H. The influence of macrosomia on the duration of labor, the mode of delivery and intrapartum complications. Arch Gynecol Obstet (2008) 278:547-53. doi: 10.1007/s00404-008-0630-7

6. Beta J, Khan N, Khalil A, Fiolna M, Ramadan G, Akolekar R. Maternal and neonatal complications of fetal macrosomia: systematic review and metaanalysis. Ultrasound Obstet Gynecol (2019) 54:308-18. doi: 10.1002/ uog. 20279

\section{DATA AVAILABILITY STATEMENT}

The raw data supporting the conclusions of this article will be made available by the authors, without undue reservation.

\section{ETHICS STATEMENT}

Ethical review and approval was not required for the study on human participants in accordance with the local legislation and institutional requirements. Written informed consent for participation was not required for this study in accordance with the national legislation and the institutional requirements.

\section{AUTHOR CONTRIBUTIONS}

Wrote the first draft of the manuscript: MP. Contributed to the writing of the manuscript: JP. Made contributions to the acquisition of the clinical data: JP and IB. Agreed with manuscript results and conclusions: JP, IB, and MP. All authors contributed to the article and approved the submitted version.

\section{ACKNOWLEDGMENTS}

The data in this manuscript have been presented as an abstract at the Endocrine Society Meeting, March 23-26, 2019, New Orleans, LA. Journal of the Endocrine Society, Volume 3, Issue Supplement_1, April-May 2019, SAT-230, https://doi.org/10. 1210/js.2019-SAT-230.

7. Sorensen HT, Sabroe S, Rothman KJ, Gillman M, Fischer P, Sorensen TI. Relation between weight and length at birth and body mass index in young adulthood: cohort study. BMJ (Clin Res Ed) (1997) 315:1137. doi: 10.1136/ bmj.315.7116.1137

8. Harder T, Rodekamp E, Schellong K, Dudenhausen JW, Plagemann A. Birth weight and subsequent risk of type 2 diabetes: a meta-analysis. Am J Epidemiol (2007) 165:849-57. doi: 10.1093/aje/kwk071

9. Tie HT, Xia YY, Zeng YS, Zhang Y, Dai CL, Guo JJ, et al. Risk of childhood overweight or obesity associated with excessive weight gain during pregnancy: a meta-analysis. Arch Gynecol Obstet (2014) 289:247-57. doi: 10.1007/s00404013-3053-z

10. Galtier-Dereure F, Boegner C, Bringer J. Obesity and pregnancy: complications and cost. Am J Clin Nutr (2000) 71:1242S-8S. doi: 10.1093/ ajcn/71.5.1242s

11. Ehrenberg HM, Dierker L, Milluzzi C, Mercer BM. Prevalence of maternal obesity in an urban center. Am J Obstet Gynecol (2002) 187:1189-93. doi: $10.1067 / \mathrm{mob} .2002 .127125$

12. Pisabarro R GM, Bermudez C, Prendez D, Recalde A, Chaftare Y, Manfredi A. Segunda encuesta nacional de sobrepeso y obesidad (ENSO2) adultos (18-65 años o mas). Rev Med Uruguay (2009) 25:14-26.

13. ACOG Practice Bulletin No. 201. Pregestational Diabetes Mellitus. Obstet Gynecol (2018) 132:e228-48. doi: 10.1097/AOG.0000000000002960

14. ACOG Practice Bulletin No. 190. Gestational Diabetes Mellitus. Obstet Gynecol (2018) 131:e49-64. doi: 10.1097/AOG.0000000000002501

15. Guariguata L, Linnenkamp U, Beagley J, Whiting DR, Cho NH. Global estimates of the prevalence of hyperglycaemia in pregnancy. Diabetes Res Clin Pract (2014) 103:176-85. doi: 10.1016/j.diabres.2013.11.003 
16. Group HSCR, Metzger BE, Lowe LP, Dyer AR, Trimble ER, Chaovarindr U, et al. Hyperglycemia and adverse pregnancy outcomes. N Engl J Med (2008) 358:1991-2002. doi: 10.1056/NEJMoa0707943

17. Li N, Liu E, Guo J, Pan L, Li B, Wang P, et al. Maternal prepregnancy body mass index and gestational weight gain on pregnancy outcomes. PLoS One (2013) 8:e82310. doi: 10.1371/journal.pone.0082310

18. Dennedy MC, Avalos G, O’Reilly MW, O’Sullivan EP, Gaffney G, Dunne F. ATLANTIC-DIP: raised maternal body mass index (BMI) adversely affects maternal and fetal outcomes in glucose-tolerant women according to International Association of Diabetes and Pregnancy Study Groups (IADPSG) criteria. J Clin Endocrinol Metab (2012) 97:E608-612. doi: 10.1210/jc.2011-2674

19. Pirkola J, Pouta A, Bloigu A, Hartikainen AL, Laitinen J, Jarvelin MR, et al. Risks of overweight and abdominal obesity at age 16 years associated with prenatal exposures to maternal prepregnancy overweight and gestational diabetes mellitus. Diabetes Care (2010) 33:1115-21. doi: 10.2337/dc09-1871

20. Pirkola J, Pouta A, Bloigu A, Miettola S, Hartikainen AL, Jarvelin MR, et al. Prepregnancy overweight and gestational diabetes as determinants of subsequent diabetes and hypertension after 20-year follow-up. J Clin Endocrinol Metab (2010) 95:772-8. doi: 10.1210/jc.2009-1075

21. Atalah E, Castillo C, Castro R, Aldea A. Proposal of a new standard for the nutritional assessment of pregnant women. Rev Med Chile (1997) 125:1429-36.

22. Ministry of Public Health. Second National Survey of Risk Factors for Noncommunicable diseases. Uruguay: Ministry of Public Health (2018). Available at: https://www.gub.uy/ministerio-salud-publica/comunicacion/publicaciones/ 2da-encuesta-nacional-de-factores-de-riesgo-de-enfermedades-no.

23. Ijas H, Koivunen S, Raudaskoski T, Kajantie E, Gissler M, Vaarasmaki M. Independent and concomitant associations of gestational diabetes and maternal obesity to perinatal outcome: A register-based study. PLoS One (2019) 14:e0221549. doi: 10.1371/journal.pone.0221549

24. Owens LA, O’Sullivan EP, Kirwan B, Avalos G, Gaffney G, Dunne F, et al. ATLANTIC DIP: the impact of obesity on pregnancy outcome in glucosetolerant women. Diabetes Care (2010) 33:577-9. doi: 10.2337/dc09-0911

25. Catalano PM, McIntyre HD, Cruickshank JK, McCance DR, Dyer AR, Metzger BE, et al. The hyperglycemia and adverse pregnancy outcome study: associations of GDM and obesity with pregnancy outcomes. Diabetes Care (2012) 35:780-6. doi: 10.2337/dc11-1790

26. Yu Z, Han S, Zhu J, Sun X, Ji C, Guo X. Pre-pregnancy body mass index in relation to infant birth weight and offspring overweight/obesity: a systematic review and meta-analysis. PLoS One (2013) 8:e61627. doi: 10.1371/journal.pone.0061627

27. Alberico S, Montico M, Barresi V, Monasta L, Businelli C, Soini V, et al. Multicentre Study Group on Mode of Delivery in Friuli Venezia G. The role of gestational diabetes, pre-pregnancy body mass index and gestational weight gain on the risk of newborn macrosomia: results from a prospective multicentre study. BMC Pregnancy Childbirth (2014) 14:23. doi: 10.1186/1471-2393-14-23

28. Dai RX, He XJ, Hu CL. Maternal pre-pregnancy obesity and the risk of macrosomia: a meta-analysis. Arch Gynecol Obstet (2018) 297:139-45. doi: 10.1007/s00404-017-4573-8

29. Koyanagi A, Zhang J, Dagvadorj A, Hirayama F, Shibuya K, Souza JP, et al. Macrosomia in 23 developing countries: an analysis of a multicountry, facilitybased, cross-sectional survey. Lancet (2013) 381:476-83. doi: 10.1016/S01406736(12)61605-5

30. Ahlsson F, Diderholm B, Jonsson B, Norden-Lindberg S, Olsson R, Ewald U, et al. Insulin resistance, a link between maternal overweight and fetal macrosomia in nondiabetic pregnancies. Hormone Res Paediatr (2010) 74:267-74. doi: 10.1159/000295710

31. Fleten C, Stigum H, Magnus P, Nystad W. Exercise during pregnancy, maternal prepregnancy body mass index, and birth weight. Obstet Gynecol (2010) 115:331-7. doi: 10.1097/AOG.0b013e3181ca4414

32. Gaudet L, Ferraro ZM, Wen SW, Walker M. Maternal obesity and occurrence of fetal macrosomia: a systematic review and meta-analysis. BioMed Res Int (2014) 2014:640291. doi: 10.1155/2014/640291

33. Mardones F, Rrosso P, Villarroel L, Burgueño L, Bacallao J, Farías M. Obesity and Underweight Diagnoses during Pregnancy using Two Standards. Ann Obes Disord (2018) 3:01-5.

34. Agudelo-Espitia V, Parra-Sosa BE, Restrepo-Mesa SL. Factors associated with fetal macrosomia. Rev Saúde Pública (2019) 100:1-10. doi: 10.11606/s15188787.2019053001269
35. Ledo Alves da Cunha AJ, Sobrino Toro M, Gutiérrez C, Alarcón-Villaverde J. Prevalencia y factores asociados a macrosomía en Perú. Rev Perú Med Exp Salud Publica (2013) 34:36-42. doi: 10.17843/rpmesp.2017.341.2765

36. Segovia Vázquez MR. Obesidad materna pregestacional como factor de riesgo para el desarrollo de macrosomía fetal. Rev Nac (Itauguá) (2014) 6:8-15.

37. Pacce S, Saure C, Mazza CS, Garcia S, Tomzig RG, Lopez AP, et al. Impact of maternal nutritional status before and during pregnancy on neonatal body composition: A cross-sectional study. Diabetes Metab Syndr (2016) 10:S7-s12. doi: 10.1016/j.dsx.2015.08.015

38. Di Benedetto A, D’Anna R, Cannata ML, Giordano D, Interdonato ML, Corrado F. Effects of prepregnancy body mass index and weight gain during pregnancy on perinatal outcome in glucose-tolerant women. Diabetes Metab (2012) 38:63-7. doi: 10.1016/j.diabet.2011.07.005

39. Tian C, Hu C, He X, Zhu M, Qin F, Liu Y, et al. Excessive weight gain during pregnancy and risk of macrosomia: a meta-analysis. Arch Gynecol Obstet (2016) 293:29-35. doi: 10.1007/s00404-015-3825-8

40. Swank ML, Caughey AB, Farinelli CK, Main EK, Melsop KA, Gilbert WM, et al. The impact of change in pregnancy body mass index on macrosomia. Obes (Silver Spring) (2014) 22:1997-2002. doi: 10.1002/oby.20790

41. Hillier TA, Pedula KL, Vesco KK, Oshiro CE, Ogasawara KK. Impact of Maternal Glucose and Gestational Weight Gain on Child Obesity over the First Decade of Life in Normal Birth Weight Infants. Matern Child Health J (2016) 20:1559-68. doi: 10.1007/s10995-016-1955-7

42. Mamun AA, O'Callaghan M, Callaway L, Williams G, Najman J, Lawlor DA. Associations of gestational weight gain with offspring body mass index and blood pressure at 21 years of age: evidence from a birth cohort study. Circulation (2009) 119:1720-7. doi: 10.1161/CIRCULATIONAHA.108.813436

43. Sridhar SB, Darbinian J, Ehrlich SF, Markman MA, Gunderson EP, Ferrara A, et al. Maternal gestational weight gain and offspring risk for childhood overweight or obesity. Am J Obstet Gynecol (2014) 211:259.e251-8. doi: 10.1016/j.ajog.2014.02.030

44. Deputy NP, Sharma AJ, Kim SY, Hinkle SN. Prevalence and characteristics associated with gestational weight gain adequacy. Obstet Gynecol (2015) 125:773-81. doi: 10.1097/AOG.0000000000000739

45. Zhu Y, Zhang C. Prevalence of Gestational Diabetes and Risk of Progression to Type 2 Diabetes: a Global Perspective. Curr Diabetes Rep (2016) 16:7. doi: 10.1007/s11892-015-0699-x

46. McIntyre HD, Catalano P, Zhang C, Desoye G, Mathiesen ER, Damm P. Gestational diabetes mellitus. Nat Rev Dis Primers (2019) 5:47. doi: 10.1038/ s41572-019-0098-8

47. Jiwani A, Marseille E, Lohse N, Damm P, Hod M, Kahn JG. Gestational diabetes mellitus: results from a survey of country prevalence and practices. $J$ Matern Fetal Neonatal Med (2012) 25:600-10. doi: 10.3109/ 14767058.2011.587921

48. Feig DS, Hwee J, Shah BR, Booth GL, Bierman AS, Lipscombe LL. Trends in incidence of diabetes in pregnancy and serious perinatal outcomes: a large, population-based study in Ontario, Canada, 1996-2010. Diabetes Care (2014) 37:1590-6. doi: 10.2337/dc13-2717

49. Albrecht SS, Kuklina EV, Bansil P, Jamieson DJ, Whiteman MK, Kourtis AP, et al. Diabetes trends among delivery hospitalizations in the U.S., 1994-2004. Diabetes Care (2010) 33:768-73. doi: 10.2337/dc09-1801

50. World Health Organization. Prevalence of obesity among adults, BMI $\geq 30$, crude Estimates by country. World Health Organization (2017). Available at: https://apps.who.int/gho/data/view.main.BMI30Cv?lang=en.

51. World Health Organization. Prevalence of obesity, crude. World Health Organization (2017). Available at: https://apps.who.int/gho/data/node.main. BMIOBESITYC?lang=en.

52. Deputy NP, Kim SY, Conrey EJ, Bullard KM. Prevalence and Changes in Preexisting Diabetes and Gestational Diabetes Among Women Who Had a Live Birth - United States, 2012-2016. MMWR Morbidity mortality Weekly Rep (2018) 67:1201-7. doi: 10.15585/mmwr.mm6743a2

53. Behboudi-Gandevani S, Amiri M, Bidhendi Yarandi R, Ramezani Tehrani F. The impact of diagnostic criteria for gestational diabetes on its prevalence: a systematic review and meta-analysis. Diabetol Metab Syndr (2019) 11:11. doi: 10.1186/s13098-019-0406-1

54. Fort Z PA, Castro M, Piñeyro C, Ciganda C, Bermúdez Y, Sandoya E. Factores de riesgo cardiovascular en 74.420 solicitantes de carné de salud. RevUrugCardiol (2012) 27:150-61. 
55. He XJ, Qin FY, Hu CL, Zhu M, Tian CQ, Li L. Is gestational diabetes mellitus an independent risk factor for macrosomia: a meta-analysis? Arch Gynecol Obstet (2015) 291:729-35. doi: 10.1007/s00404-014-3545-5

56. Riskin-Mashiah S, Younes G, Damti A, Auslender R. First-trimester fasting hyperglycemia and adverse pregnancy outcomes. Diabetes Care (2009) 32:1639-43. doi: 10.2337/dc09-0688

57. Stotland NE, Caughey AB, Breed EM, Escobar GJ. Risk factors and obstetric complications associated with macrosomia. Int J Gynaecol Obstet (2004) 87:220-6. doi: 10.1016/j.ijgo.2004.08.010

58. Group HSCR. The Hyperglycemia and Adverse Pregnancy Outcome (HAPO) Study. Int J Gynaecol Obstet (2002) 78:69-77. doi: 10.1016/S0020-7292(02) 00092-9

59. Zhu Y, Olsen SF, Mendola P, Yeung EH, Vaag A, Bowers K, et al. Growth and obesity through the first $7 \mathrm{y}$ of life in association with levels of maternal glycemia during pregnancy: a prospective cohort study. Am J Clin Nutr (2016) 103:794-800. doi: 10.3945/ajcn.115.121780

60. Catalano PM. Obesity and pregnancy-the propagation of a viscous cycle? J Clin Endocrinol Metab (2003) 88:3505-6. doi: 10.1210/jc.2003-031046

61. Lau C, Rogers JM, Desai M, Ross MG. Fetal programming of adult disease: implications for prenatal care. Obstet Gynecol (2011) 117:978-85. doi: 10.1097/AOG.0b013e318212140e

62. Vickers $\mathrm{MH}$. Developmental programming and transgenerational transmission of obesity. Ann Nutr Metab (2014) 64(Suppl 1):26-34. doi: 10.1159/000360506

63. Padmanabhan V, Cardoso RC, Puttabyatappa M. Developmental Programming, a Pathway to Disease. Endocrinology (2016) 157:1328-40. doi: 10.1210/en.2016-1003

64. Langmia IM, Kräker K, Weiss SE, Haase N, Schütte T, Herse F, et al. Cardiovascular Programming During and After Diabetic Pregnancy: Role of Placental Dysfunction and IUGR. Front Endocrinol (Lausanne) (2019) 10:215. doi: 10.3389/fendo.2019.00215

65. Johnson K, Posner SF, Biermann J, Cordero JF, Atrash HK, Parker CS, et al. Recommendations to improve preconception health and health care-United States. A report of the CDC/ATSDR Preconception Care Work Group and the Select Panel on Preconception Care. MMWR Recommendations Rep Morbidity mortality Weekly Rep Recommendations Rep (2006) 55:1-23. doi: 10.1037/e506902006-001

66. Crozier SR, Robinson SM, Borland SE, Godfrey KM, Cooper C, Inskip HM. Do women change their health behaviours in pregnancy? Findings from the Southampton Women's Survey. Paediatr Perinat Epidemiol (2009) 23:446-53. doi: 10.1111/j.1365-3016.2009.01036.x

67. Oteng-Ntim E, Varma R, Croker H, Poston L, Doyle P. Lifestyle interventions for overweight and obese pregnant women to improve pregnancy outcome: systematic review and meta-analysis. BMC Med (2012) 10:47. doi: 10.1186/ 1741-7015-10-47

68. Muktabhant B, Lawrie TA, Lumbiganon P, Laopaiboon M. Diet or exercise, or both, for preventing excessive weight gain in pregnancy. Cochrane Database Syst Rev (2015) Cd007145. doi: 10.1002/14651858.CD007145.pub3
69. Horvath K, Koch K, Jeitler K, Matyas E, Bender R, Bastian H, et al. Effects of treatment in women with gestational diabetes mellitus: systematic review and meta-analysis. BMJ (Clin Res Ed) (2010) 340:c1395. doi: 10.1136/bmj.c1395

70. Rey E, Attie C, Bonin A. The effects of first-trimester diabetes control on the incidence of macrosomia. Am J Obstet Gynecol (1999) 181:202-6. doi: 10.1016/S0002-9378(99)70460-6

71. Duryea EL, Hawkins JS, McIntire DD, Casey BM, Leveno KJ. A revised birth weight reference for the United States. Obstet Gynecol (2014) 124:16-22. doi: 10.1097/AOG.0000000000000345

72. Ju H, Chadha Y, Donovan T, O’Rourke P. Fetal macrosomia and pregnancy outcomes. Aust N Z J Obstet Gynaecol (2009) 49:504-9. doi: 10.1111/j.1479828X.2009.01052.x

73. Spellacy WN, Miller S, Winegar A, Peterson PQ. Macrosomia-maternal characteristics and infant complications. Obstet Gynecol (1985) 66:158-61.

74. Thomson AM, Billewicz WZ, Hytten FE. The assessment of fetal growth. J Obstetr Gynaecol Br Commonwealth (1968) 75:903-16. doi: 10.1111/j.14710528.1968.tb01615.x

75. Di Renzo GC, Rosati A, Sarti RD, Cruciani L, Cutuli AM. Does fetal sex affect pregnancy outcome? Gender Med (2007) 4:19-30. doi: 10.1016/S1550-8579 (07)80004-0

76. Dai RX, He XJ, Hu CL. The Association between Advanced Maternal Age and Macrosomia: A Meta-Analysis. Childhood Obes (Print) (2019) 15:149-55. doi: 10.1089/chi.2018.0258

77. Jolly MC, Sebire NJ, Harris JP, Regan L, Robinson S. Risk factors for macrosomia and its clinical consequences: a study of 350,311 pregnancies. Eur J Obstet Gynecol Reprod Biol (2003) 111:9-14. doi: 10.1016/S0301-2115 (03)00154-4

78. Agarwal MM. Gestational diabetes mellitus: Screening with fasting plasma glucose. World J Diabetes (2016) 7:279-89. doi: 10.4239/wjd.v7.i14.279

79. Hartling L, Dryden DM, Guthrie A, Muise M, Vandermeer B, Donovan L. Benefits and harms of treating gestational diabetes mellitus: a systematic review and meta-analysis for the U.S. Preventive Services Task Force and the National Institutes of Health Office of Medical Applications of Research. Ann Internal Med (2013) 159:123-9. doi: 10.7326/0003-4819-159-2-201307160-00661

80. Headen I, Cohen AK, Mujahid M, Abrams B. The accuracy of self-reported pregnancy-related weight: a systematic review. Obes Rev (2017) 18:350-69. doi: $10.1111 /$ obr.12486

Conflict of Interest: The authors declare that the research was conducted in the absence of any commercial or financial relationships that could be construed as a potential conflict of interest.

Copyright (c) 2020 Pereda, Bove and Pineyro. This is an open-access article distributed under the terms of the Creative Commons Attribution License (CC BY). The use, distribution or reproduction in other forums is permitted, provided the original author(s) and the copyright owner(s) are credited and that the original publication in this journal is cited, in accordance with accepted academic practice. No use, distribution or reproduction is permitted which does not comply with these terms. 